\title{
Superoxide Dismutase (SOD) Activity in Cryopreserved Semen of Itik Pinas-Khaki (Anas platyrhynchos L.)
}

\author{
A. E. Ancuelo, M. M. Landicho, G. A. Dichoso, \& P. P. Sangel* \\ Institute of Animal Science, College Agriculture and Food Science, University of the Philippines Los Baños, College \\ 4031 Los Baños, Laguna, Philippines \\ *Corresponding author: ppsangel@up.edu.ph \\ (Received 30-06-2020; Revised 23-09-2020; Accepted 19-10-2020)
}

\begin{abstract}
Cryopreservation induces oxidative stress on sperm due to an increase in the number of reactive oxygen species (ROS), thereby resulting in decreased sperm quality. ROS's destructive potential is normally counteracted in sperm by their innate antioxidant system consisting of enzymes, which include superoxide dismutase (SOD). This study aimed to assess the quality of semen from Itik Pinas-Khaki (IP-Khaki) drakes that were cryopreserved with either $4.5 \%$ DMSO or $7.0 \%$ glycerol as cryoprotectant through evaluation of total sperm motility (\%) and determination of SOD activity (U/ $\mathrm{mL}$ ). Here, semen samples were collected from 12 sexually mature IP-Khaki drakes, an improved egg-type breed of Philippine mallard duck, and processed using modified reported cryopreservation procedure for ducks. Results showed that post-thawing total sperm motility averages of $12.04 \pm 5.61 \%$ using $4.5 \%$ DMSO and $13.99 \pm 5.28 \%$ using $7.0 \%$ glycerol were comparable. Moreover, similar SOD activity levels of $0.39 \pm 0.18 \mathrm{U} / \mathrm{mL}$ with $4.5 \%$ DMSO and $0.33 \pm 0.21 \mathrm{U} / \mathrm{mL}$ with $7.0 \%$ glycerol in $2.00 \times 10^{8}$ IP-Khaki sperm cells were also observed. The observed very low intracellular SOD activity indicates severe damage to sperm cells due to cryopreservation, which resulted in a comparably low total sperm motility with either of the cryoprotectants. Thus, the cryopreservation protocol used is not the optimum for IP-Khaki semen based on the observed considerable decline in sperm motility and very low SOD activity after cryopreservation.
\end{abstract}

Keywords: cryopreservation; itik pinas; semen; SOD assay

\section{INTRODUCTION}

Semen cryopreservation has gained attention due to its potential application in the breeding selection, disease prevention, and conservation of genetic resources (Zaniboni et al., 2014). The process generally involves long-term storage of cells in a medium supplemented with cryoprotective agents (CPA) at extremely low temperatures to preserve their functionality (Elliot et al., 2017). Allowing prolonged semen storage can also help in the conservation of endangered species and propagate essential animal breeds (Comizzoli, 2015; Thelie et al., 2019). The technique is indeed beneficial; however, its widespread application is challenged by the variability in responses observed from species to species (Rakha et al., 2016) and the stress introduced to cells during processing, storage, and thawing which affects semen quality (Tatone et al., 2010). Previous studies had also reported an observed increase in intracellular reactive oxygen species (ROS) levels, which can be associated with a decrease in sperm quality during cryo-processing and after thawing (Evangelista-Vargas \& Santiani, 2017; Kim et al., 2011; Slowinska et al., 2018; Tatone et al., 2010). In response to unfavorable conditions, sperm cells tend to produce an increased ROS amount (Khan,
2011). However, ROS's unrestrained levels can result in oxidative stress, which alters cellular pathways and causes membrane damage, decreased sperm function, and DNA damage (Aitken, 2020).

To counteract the destructive effects of increased ROS levels, the sperm is protected by antioxidants which include the enzymes superoxide dismutase (SOD), glutathione peroxidase (GSH-Px), and catalase (Bansal \& Bilaspuri, 2011). Superoxide anion $\left(\mathrm{O}_{2}^{-}\right)$, constantly being produced through different pathways or chain reactions (Ighodaro \& Akinloye, 2018), reacts with hydrogen ions in the dismutation reaction catalyzed by SOD to form hydrogen peroxide $\left(\mathrm{H}_{2} \mathrm{O}_{2}\right)$ and oxygen $\left(\mathrm{O}_{2}\right): 2 \mathrm{O}_{2}^{-}+2 \mathrm{H}^{+} \rightarrow \mathrm{H}_{2} \mathrm{O}_{2}+\mathrm{O}_{2}$ (Partyka et al., 2012b). The $\mathrm{H}_{2} \mathrm{O}_{2}$ produced from this reaction will then be converted to water and oxygen with the aid of CAT and/or GSH-Px (Surai, 2016). SOD, the first line of defense against $\mathrm{O}_{2}$, has three isoforms: cytosolic $\mathrm{Cu} / \mathrm{Zn} \mathrm{SOD}$, mitochondrial Mn-SOD, and extracellular EC-SOD (Surai, 2016; Surai et al., 2019; Wang et al., 2018). As it is involved in the defense against ROS, this enzyme can be an indicator of oxidative stress by directly measuring its activity. Several studies investigated the activity of this enzyme in cryopreserved semen. A significant decrease in intracellular SOD activity was observed after cryopreserva- 
tion in a rooster (Partyka et al., 2012a), bull (Kadirve et al., 2014), dog (Strzeżek et al., 2012), and ram (Marti et al., 2008) sperm. Association between SOD activity and common sperm parameters such as motility, membrane integrity, and viability has also been observed (Lone et al., 2018; Perumal, 2014; Zakošek Pipan et al., 2014), making it an excellent indicator of good semen quality.

In the Philippines, efforts are being exerted to preserve the diverse and rich genetic resources of native fowls such as the Itik Pinas (IP). IP is an improved egg-type Philippine mallard duck (Anas platyrhynchos L.), which is a product of continuous and organized breeding and selection of the traditional or Pateros duck commonly raised in the country. IP has uniform physical characteristics, higher and predictable egg production performance, and consistent egg quality. Moreover, IP even performs well with simple housing and low-cost feeds since they are easily adapted to the local environmental conditions (Parungao, 2016; Parungao, 2017; Aya, 2018; Pinca et al., 2019). IP has three developed strains- IP-Itim, IP-Khaki (both are pure lines), and IP-Kayumanggi (commercial hybrid line). Cryopreservation protocol for these genetic lines has not been fully developed yet, hence requiring an initial investigation to further improve the procedure. Therefore, this study assessed the suitability of modified duck semen cryopreservation methods in IP semen. This study also evaluated the oxidative stress level between the use of $4.5 \%$ dimethyl sulfoxide (DMSO) and $7.0 \%$ glycerol as cryoprotectant through superoxide dismutase (SOD) assay.

\section{MATERIALS AND METHODS}

All procedures were subjected to the evaluation and approval of the Institutional Animal Care and Use Committee (IACUC) of the University of the Philippines Los Baños (UPLB) with assigned protocol number CAFS-2018-006. Semen collection from experimental drakes was done at the University Animal Farm in Putho-Tuntungin, Los Baños, Laguna, Region IV-A, Philippines $\left(14^{\circ} 09^{\prime} 24.4^{\prime \prime} \mathrm{N}, 121^{\circ} 15^{\prime} 06.6^{\prime \prime} \mathrm{E}\right)$. Semen processing and evaluation were conducted at the Animal Physiology Laboratory, Institute of Animal Science (IAS), College of Agriculture and Food Science (CAFS), UPLB.

\section{Experimental Design}

The experiment was carried out using a two-way repeated measures design to test the SOD activity of the post-thawed cryopreserved semen using either $4.5 \%$ DMSO or $7.0 \%$ glycerol as cryoprotectant. A total of 36 semen samples which were individually collected from 12 sexually mature Itik Pinas-Khaki (IP-Khaki) drakes (14-mo-old and with an average weight of $1.36 \mathrm{~kg}$ ) over 3 collection periods, were used in this study.

\section{Management and Care of Native Ducks}

Twenty-five (25) 3-month old IP-Khaki drakes were acquired from the National Swine and Poultry
Research and Development Center, Bureau of Animal

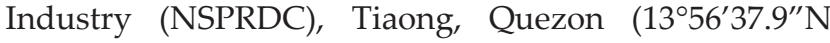
$\left.121^{\circ} 22^{\prime} 23.6^{\prime \prime} \mathrm{E}\right)$. These ducks were housed in individual cages with optimized conditions and raised to maturity following the management procedures and flock health program in the University Animal Farm located at Putho-Tuntungin, Los Baños, Laguna $\left(14^{\circ} 08^{\prime} 46.2^{\prime \prime} \mathrm{N}\right.$ $\left.121^{\circ} 15^{\prime} 08.7^{\prime \prime} \mathrm{E}\right)$. They were fed with standard commercial duck feeds and given unlimited access to potable drinking water. Every day, feces were scraped using a shovel, and cages were washed with water and disinfectant. Upon reaching sexual maturity, the native drakes underwent semen collection training daily using the dorso-abdominal massage method (Burrows and Quinn, 1935), which spans about 1-2 min for 3 consecutive weeks. After training, semen collection was done routinely every other day. Twelve (12) out of Twenty-Five (25) drakes were randomly selected for this study.

\section{Semen Collection}

Semen collection was done every other day at 07:00 AM by one trained personnel at the farm. Special attention and caution were strictly observed to avoid fecal or dirt contamination during semen collection. Furthermore, a 17-h interval from feeding to the collection was also done to avoid defecation upon collection. Removal and plucking of feathers at the peri-cloacal region were also done to prevent the semen samples' dirt contamination. The entire semen collection period usually takes about 5-10 min. Upon collection, the fresh semen samples were first evaluated according to their gross characteristics. Among the parameters observed were consistency (i.e., either watery or creamy via visual appraisal), ejaculate volume (i.e., using a sterile disposable $1 \mathrm{~mL}$ syringe with $0.01 \mathrm{~mL}$ calibration), and $\mathrm{pH}$ (i.e., using $\mathrm{pH}$ indicator paper strips). The semen sample in $1 \mathrm{~mL}$ syringe was immediately placed inside a sterile beaker with a sterile cloth and placed inside a clean and disinfected foam-padded icebox held at room temperature and sent to the laboratory for further analysis. The entire sample transportation time took about 5-10 minutes. The procedure was done for 3 collection periods spread out from October to November 2019.

\section{Semen Quality Evaluation}

The same personnel conducted the macroscopic evaluation of individual semen samples right after collection. The color, consistency, ejaculate volume $(\mathrm{mL})$, and $\mathrm{pH}$ of individual semen samples were recorded prior to dilution with modified Lake's Fowl Semen Extender (LFSE) (Bootwalla \& Miles, 1992). The diluent used had the following composition per liter: fructose $(10 \mathrm{~g})$, magnesium chloride $(0.68 \mathrm{~g})$, trisodium citrate $(1.28 \mathrm{~g})$, sodium acetate $(8.51 \mathrm{~g})$, and sodium glutamate (19.20 g). Trisodium citrate, which can also function as a buffer in semen diluents (Nor-Ashikin \& Abdullah, 2011), was used as a substitute for tripotassium citrate. Based on observed consistency, a 1:36 and 1:18 ratio was used to dilute creamy and watery ejaculates, respectively, initially. The dilution ratio used was based on 
previous observations on the semen dilution readable by the equipment used for sperm motility assessment (Capitan \& Palad, 1999; Esguerra et al., 2020).

Microscopic semen characteristics such as sperm concentration and total sperm motility were also assessed and recorded. Semen concentration in sperm/ $\mathrm{mL}$ was obtained using a hemocytometer slide as described by Capitan and Palad (1999). Before loading diluted semen samples into the dilution pipette for sperm concentration determination, each was gently and consistently mixed to allow uniform distribution of cells in the diluent. Cells were stained 1:200 using the dilution pipette with $0.1 \%(\mathrm{w} / \mathrm{v})$ nigrosin before loading onto the Neubauer chamber (Max Levy, USA). Nigrosin was used as a negative stain to have clearer visibility of sperm during the manual microscopic counting. The initial dilution with modified LFSE was considered in the calculation to obtain the pure semen concentration of each sample. Meanwhile, total sperm motility (\%) in previously diluted semen samples was evaluated using a computer assisted semen analyzer (CASA) (Ceros II, IMV Technologies, China) with Anas platyrhynchos setup/module at a frame capture speed of $60 \mathrm{~Hz}$ and camera exposure of $4 \mathrm{~ms}$, where five (5) frames were captured for every analysis. The entire sperm motility analysis took an average time of one min to finish.

\section{Semen Cryopreservation}

The 36 ejaculates were cryopreserved using the general freezing procedure described by Han et al. (2005), with modification on the diluent and its ratio, inclusion rate of each cryoprotectant, equilibration, and thawing. After being held at $5^{\circ} \mathrm{C}$ for $2 \mathrm{~h}$, the extended semen samples were divided into two equal volumes and assigned to two types of cryoprotectant (i.e., DMSO or glycerol). Each cryoprotectant was mixed with LFSE and added to the extended cooled semen to a final inclusion rate of $4.5 \%$ for DMSO (Vivantis Inc., USA) as adopted from Van Voorst et al. (1995) and 7.0\% for glycerol (Life Technologies Corp., USA) as adopted from Rakha et al. (2018). The ejaculates were diluted to a final concentration of $2.00 \times 10^{8} \mathrm{sperm} / \mathrm{mL}$ and held again at $5{ }^{\circ} \mathrm{C}$ for another hour, instead of two hours. The sperms were packed in 1.5-mL microcentrifuge tubes and pre-frozen in microcentrifuge tube freezing racks that were held 5 $\mathrm{cm}$ above the surface of liquid nitrogen for $10 \mathrm{~min}$. The samples were submerged in liquid nitrogen at $-196{ }^{\circ} \mathrm{C}$ and stored for at least $24 \mathrm{~h}$. Using a water bath, cryopreserved semen samples were thawed at $37^{\circ} \mathrm{C}$ for $1 \mathrm{~min}$. Post-thawing total sperm motility (\%) was assessed and recorded using CASA following the procedures previously described.

\section{Determination of SOD Activity}

To measure the superoxide dismutase (SOD) activity of the frozen-thawed semen samples, a commercially available SOD colorimetric activity kit (Life Technologies Corporation, USA) was used following the manufacturer's recommendation. Cell lysates for the assay were prepared using the Tissue Protein Extraction
Reagent (T-PER ${ }^{\mathrm{TM}}$ ) (Life Technologies Holdings Pte Ltd, Singapore) as the lysis buffer. Thawed semen samples with a concentration of $2.00 \times 10^{8} \mathrm{sperm} / \mathrm{mL}$ were centrifuged at $3500 \times \mathrm{g}$ for $1 \mathrm{~min}$ (Borziak et al., 2016) at room temperature. The cell pellets were washed once with 100 $\mu \mathrm{L}$ ice-cold Phosphate-buffered Saline (PBS, pH 7.4), then vortexed for 10-15 secs. The cells were recovered again by centrifugation at $3500 \times \mathrm{g}$ for $1 \mathrm{~min}$ at room temperature. About $50 \mu \mathrm{L}$ of ice-cold lysis buffer was added to the cell pellet, then vortexed for 10-15 seconds. The cell lysates were kept in ice for a maximum of 20 min prior to assay.

Cell lysates were diluted 1:4 in the assay buffer. Standard curve was constructed using SOD standards with concentrations $(\mathrm{U} / \mathrm{mL}) 2,1,0.5,0.25,0.125,0.0625$ and 0 . About $10 \mu \mathrm{L}$ of standard or diluted samples with $50 \mu \mathrm{L} 1 \mathrm{X}$ substrate were added to the assigned wells. The lysis buffer was used as the blank. About 25 $\mu \mathrm{L}$ of the chromogenic detection reagent: 1X Xanthine Oxidase was also added into each well. The mixture was incubated for $20 \mathrm{~min}$ at room temperature. The absorbance was read at $450 \mathrm{~nm}$ using the Multiskan Sky Microplate Spectrophotometer (Life Technologies Holdings Pte Ltd, Singapore). SOD activity in U/mL was calculated by SkanIt ${ }^{\mathrm{TM}}$ Software for Microplate Readers using the SOD quantification protocol. All assays for the standard and samples were done in duplicate.

\section{Statistical Analysis}

All data were analyzed using a two-factor repeated measures analysis of variance (ANOVA). The level of significance was set at $p \leq 0.05$. Descriptive values were expressed as mean \pm SD. All statistical analyses were done using IBM SPSS software (IBM Corp., Armonk, N.Y., USA).

\section{RESULTS}

\section{Semen Quality Evaluation}

Consistency, ejaculate volume, and $\mathrm{pH}$ from IP- Khaki semen were all observed in this study $(n=36)$ (Table 1$)$. Thirty-one (31) ejaculates $(86.11 \%)$ were thick and creamy, while 5 ejaculates $(13.89 \%)$ were thin and milky white, indicating good semen quality (Churchil et al., 2014). The ejaculate volume ranged from 0.06 to $0.22 \mathrm{~mL}$ with an average of $0.14 \pm 0.09 \mathrm{~mL}$ while the $\mathrm{pH}$ ranged from 6.60 to 7.40 with an average of $6.99 \pm 0.19$. Sperm concentration ranged from $7.11-15.56 \times 10^{9} \mathrm{sperm} /$ $\mathrm{mL}$, with an average of $10.85 \times 10^{9} \pm 0.22$ sperm $/ \mathrm{mL}$. The average initial total sperm motility recorded was $75.70 \pm 12.90 \%$.

\section{Semen Cryopreservation}

The post-thawing total sperm motility of frozen IPKhaki semen using either $4.5 \%$ DMSO or $7.0 \%$ glycerol was assessed. The post-thawing total sperm motility of samples ranged from $2.90 \%$ to $23.62 \%$ with an average of $12.04 \pm 5.61 \%$ for $4.5 \%$ DMSO and $4.0 \%$ to $27.30 \%$ with an average of $13.99 \pm 5.28 \%$ for $7.0 \%$ glycerol. A signifi- 
cant decrease of $83.97 \pm 0.07 \%$ with $4.5 \%$ DMSO $(p<0.05)$ and $81.11 \pm 0.07 \%$ with $7.0 \%$ glycerol $(p<0.05)$ from the initial average total sperm motility in IP-Khaki was observed (Figure 1).

\section{Determination of SOD Activity}

Due to the relatively high drop in post-thawing total sperm motility of IP-Khaki semen, the stress level between samples with $4.5 \%$ DMSO and $7.0 \%$ glycerol as cryoprotectant was measured using SOD Colorimetric Assay as previously described. Results showed that the average enzymatic activity of SOD in IP-Khaki frozen-thawed semen, with a concentration of $2.00 \times 10^{8}$ sperm $/ \mathrm{mL}$, were $0.39 \pm 0.18 \mathrm{U} / \mathrm{mL}$ with $4.5 \%$ DMSO and $0.33 \pm 0.21 \mathrm{U} / \mathrm{mL}$ with $7.0 \%$ glycerol (Table 2 ).

\section{DISCUSSION}

The observed average ejaculate volume falls within the reported range of $0.10-0.70 \mathrm{~mL}$ in Pekin ducks (Surai \& Wishart, 1996). It is also close to the reported semen volume of $0.16 \mathrm{~mL}$ in White Pekin and $0.18 \mathrm{~mL}$ in Kuttanad (local strain from India) (Cyriac et al., 2013). Meanwhile, the observed average $\mathrm{pH}$ of IP-Khaki semen is close to the reported $\mathrm{pH}$ of 7.10 in local Iraqi drakes (Mossa, 2006). A slightly comparable $\mathrm{pH}$ of 6.90 and 6.83 were also observed in the semen of Polish duck strains, particularly in KhO-01 (i.e., a cross between Khaki Campbell and reddish Orpington ducks) and K2 (i.e., cross between light Peking ducks and wild ducks), respectively (Zawadzka et al., 2015). Differences between the observed values and previously reported values can be attributed to several factors such as seasonal variation, age at sexual maturity, frequency of collection, genetic makeup, body weight, breed differences, and diet

Table 1. Gross and microscopic semen characteristics of Itik Pinas (IP)- Khaki ( $\mathrm{n}=36)$

\begin{tabular}{lc}
\hline \multicolumn{1}{c}{ Variables } & Mean \pm SD \\
\hline Volume $(\mathrm{mL})$ & $0.14 \pm 0.09$ \\
$\mathrm{pH}$ & $6.99 \pm 0.19$ \\
Concentration $\left(\times 10^{9}\right.$ cells $\left./ \mathrm{mL}\right)$ & $10.85 \pm 0.22$ \\
Initial total sperm motility $(\%)$ & $75.70 \pm 12.90$ \\
\hline
\end{tabular}

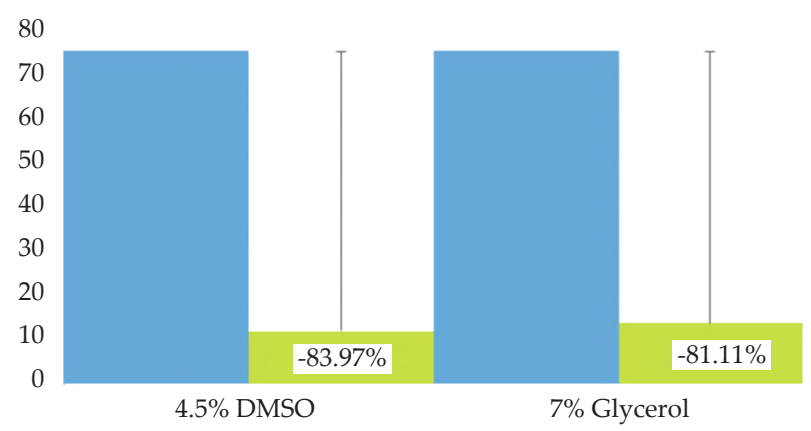

Figure 1. Decrease in \% total sperm motility of IP-Khaki semen after cryopreservation using either $4.5 \%$ dimethyl sulfoxide (DMSO) or $7.0 \%$ glycerol as cryoprotectant. $\amalg=$ initial motility $(\%)$; $₫=$ post-thawing motility $(\%)$.
(Malik et al., 2013; Saint Jalme et al., 2003). Though pH of semen during processing is expected to lower as a result of the metabolic activities of sperm cells over time, it is important to maintain and control a favorable $\mathrm{pH}$ as this factor influences sperm motility, where lower $\mathrm{pH}$ such as in acidic environment results to lower sperm motility (Zawadzka et al., 2015).

The average sperm concentration value from IPKhaki was higher than the reported concentration values of $8.50 \times 10^{9}$ sperm $/ \mathrm{mL}$ and $6.90 \times 10^{9}$ sperm $/ \mathrm{mL}$ from KhO-01 and K2, respectively (Zawadzka et al., 2015). A concentration of $3.20 \times 10^{9}$ sperm/mL on Osaka duck can be obtained through manual massage and $7.00 \times 10^{9}$ sperm/mL through an artificial vagina, according to Kasai \& Izumo (2001). Differences in the observed values may be attributed to varying factors, which include collection interval, semen volume, and individual variation between animals (Nahak et al., 2015). It is necessary to determine the sperm concentration as it dictates the dilution rate needed for further processing of semen, just like simple extension or cryopreservation. Sperm concentration is necessary to obtain acceptable fertility results crucial to the AI industry (Mohanty et al., 2018).

The initial total sperm motility of diluted IP-Khaki semen used in the study was higher than fresh semen motility of $60.83 \%$ in Muscovy ducks, $58.33 \%$ in Kuttanad ducks, and $57.50 \%$ in White Pekin reported by Cyriac et al. (2013). Higher initial total sperm motility observed in IP-Khaki semen can be attributed to the use of semen extender to maintain its quality while being analyzed (Gerzilov et al., 2011). On the other hand, Polish duck strains exhibited an average of $76.28 \%$ and $74.66 \%$ sperm motility for $\mathrm{KhO}-01$ and $\mathrm{K} 2$, respectively (Zawadzka et al., 2015).

The observed post-thawing motility in IP-Khaki semen with $4.5 \%$ DMSO was higher compared to the observed $6.87 \%$ sperm motility in Jinding duck semen cryopreserved with $4.0 \%$ DMSO, while the average postthawing total sperm motility in IP- Khaki semen using $7.0 \%$ glycerol was found inferior to the recorded $68.12 \%$ sperm motility in Jinding duck semen with glycerol at $8.0 \%$ inclusion rate (Han et al., 2005). According to Han et al. (2005), 8.0\% was the most effective inclusion rate of glycerol, while $4.0 \%$ was the least effective for DMSO. The difference between the observed motility with $4.0 \%$ DMSO and $8.0 \%$ glycerol in this previous study is very evident. In the conducted experiment, the amount used for DMSO and glycerol is slightly close to the amount used in the mentioned study. However, results for both

Table 2. Mean SD of post-thawing total sperm motility and SOD activity of IP-Khaki semen cryopreserved using different types of cryoprotectant

\begin{tabular}{lccc}
\hline \multicolumn{1}{c}{ Variables } & \multicolumn{2}{c}{ Cryoprotectant } & p-value \\
\cline { 2 - 3 } & $4.5 \%$ DMSO & $7.0 \%$ Glycerol & \\
\hline $\begin{array}{l}\text { Post-thawing total } \\
\text { sperm motility }(\%)\end{array}$ & $12.04 \pm 5.61$ & $13.99 \pm 5.28$ & 0.11 \\
$\begin{array}{l}\text { SOD activity } \\
(\mathrm{U} / \mathrm{mL})\end{array}$ & $0.39 \pm 0.18$ & $0.33 \pm 0.21$ & 0.20 \\
\hline
\end{tabular}

Note: ${ }^{*} \mathrm{p} \leq 0.05$ is significant; $\mathrm{DMSO}=$ dimethyl sulfoxide; $\mathrm{SOD}=$ superoxide dismutase. 
cryoprotectants were comparable. Low total sperm motility observed in thawed semen samples for both cryoprotectant and the significant decrease from the initial to post-thawing total sperm motility indicates that the adapted procedure was not suitable for IP-Khaki semen. This can be attributed to several factors that affect semen cryosurvival, such as the kind and concentration of cryoprotectant used (Di Iorio et al., 2020), and the innate characteristics of the semen donor (Blanco et al., 2011). IP, being an improved duck breed, may have fragile sperm composition compared to other breeds (Surai et al., 2000; Chen et al., 2016; Majhi et al., 2016; Atifah et al., 2018). In this case, the amount of cryoprotectant used for semen cryopreservation from other breeds may not be appropriate in the cryopreservation of IP-Khaki semen.

The results of the study suggest that the semen cryopreservation method for IP-Khaki semen needs further optimization. The type of diluent, as well as the type and inclusion level of cryoprotectant, may be modified again to obtain better results (Gerzilov, 2010; Rakha et al., 2018; Di Iorio et al., 2020). Previously reported studies on rooster semen cryopreservation showed that the inclusion levels of DMSO or glycerol can vary depending on the cryopreservation procedure and the animal breed used, suggesting that a single protocol will not always work for all breeds (Blanch et al., 2014; Khaeruddin et al., 2019; Long et al., 2010; Pelaez et al., 2011; Svoradová et al., 2018; Telnoni et al., 2017). In rooster semen cryopreservation, a higher inclusion of DMSO [i.e., 7.0\% (Khaeruddin et al. 2019) and 10.0\% DMSO (Telnoni et al., 2017)] was used. An inclusion rate of $10.0 \%$ DMSO also worked well in Jinding duck semen's cryopreservation, but in a different extender (Han et al., 2005). In this study, the inclusion rate of DMSO was reduced (Van Voorst et al., 1995); however, the reduced amount of DMSO may not have improved sperm cell recovery after cryopreservation. For the cryopreservation of IP semen, the effect of increasing the amount of DMSO can be further investigated. The amount of glycerol used, on the other hand, is slightly lower than $8.0 \%$, which was also used in other avian species (Blanch et al., 2014; Svoradová et al. 2018; Abouelezz et al., 2017). However, the results obtained in this cryoprotectant is comparable with DMSO. In this case, varying the extender can be done.

The need to develop a suitable extender with complementary type and inclusion level of cryoprotectant can further contribute to successful semen cryopreservation efforts in IP, which can be an important tool for their propagation and conservation. Furthermore, equilibration time and thawing rate should also be given attention in developing an efficient and working protocol (Blanco et al., 2012; Mphaphathi et al., 2012). Overall, optimization of these factors is necessary to lessen various stresses on the physical properties of IP sperm and of its chemical components necessary for its functions, such as energy metabolism for good motility (Long, 2006; Blanco et al., 2011). This will improve the recovery of semen subjected to freezing and thawing.

Activity assay for antioxidant enzymes such as SOD, GSH-Px, and CAT has been commonly used to assess oxidative stress in animals' specimens ( $\mathrm{Hu}$ et al., 2010; Aramli et al., 2013; Orzołek et al., 2013). The sperm motility of frozen-thawed semen samples with DMSO or glycerol as cryoprotectant was analyzed and compared as previously discussed. Similarly, the SOD activity of cryopreserved IP-Khaki semen showed no significant difference between the two groups. This suggests that both cryoprotectants used have a comparable oxidative stress level on IP- Khaki semen during processing, resulting in comparable recovery rates after thawing.

A previous study in chicken decreased intracellular SOD activity, from $40.7 \pm 6.2 \mathrm{U} / 10^{9}$ sperm cells to $28.6 \pm 7.7$ $\mathrm{U} / 10^{9}$ sperm cells, was reported after cryopreservation (Partyka et al., 2012a). This showed that the decrease in intracellular SOD activity due to cryopreservation might have influenced the increase in lipid peroxidation, thereby decreasing the sperm quality. In the present study, an SOD activity of $1.95 \mathrm{U} / 10^{9}$ sperm with $4.5 \%$ DMSO and $1.65 \mathrm{U} / 10^{9}$ sperm with $7.0 \%$ glycerol (values computed from $0.39 \pm 0.18 \mathrm{U} / \mathrm{mL}$ with $4.5 \%$ DMSO and $0.33 \pm 0.21 \mathrm{U} / \mathrm{mL}$ with $7.0 \%$ glycerol with $2.00 \times 10^{8}$ sperm/ $\mathrm{mL}$ final concentration) was recorded. This is very low compared to the recorded SOD activity of $59.91 \mathrm{U} / 10^{9}$ in fresh duck sperm by Surai et al. (1998), 44.0 \pm 4.0 in fresh chicken sperm (Patyka et al. 2012b), and 308.5 \pm 116.4 in fresh goose sperm (Patyka et al. 2012b).

During cryopreservation, the decrease in SOD can be attributed to the leakage of intracellular enzymes due to membrane damage, as indicated by the previously observed increase in SOD activity in the seminal plasma of chickens (Partyka et al. 2012a), humans (Lasso et al. 1994), and fishes (Huang et al., 2014a; Huang et al., 2014b; Wang et al., 2016), after cryopreservation. In the present study, extreme membrane damage might have caused the very low intracellular SOD activity and very low total sperm motility, resulting from the cryopreservation protocol applied. For future studies, it is recommended to measure both the SOD activity in seminal plasma and sperm cells before and after cryopreservation. It is also highly recommended to assess the membrane damage caused by the cryopreservation process. Aside from SOD, the activity of other antioxidant enzymes can also be measured. Supplementation of SOD (Partyka et al. 2013) in IP semen to improve cell recovery can also be done since the observed SOD activity is very low.

\section{CONCLUSION}

A considerable decline in motility and very low SOD activity were observed, thus indicating possible membrane damage that resulted from the cryopreservation procedure used. The use of either $4.5 \%$ DMSO or $7.0 \%$ glycerol as cryoprotectants showed comparable results. Therefore, both the inclusion of the two cryoprotectants used and the cryopreservation procedure applied were not optimum for IP-Khaki semen cryopreservation.

\section{CONFLICT OF INTEREST}

All authors have no conflict of interest to declare. 


\section{ACKNOWLEDGEMENT}

This work was supported by the Department of Agriculture - Bureau of Agricultural Research (DABAR) through the DA-BIOTECH program funded project entitled, "Development of cryopreservation prototypes as biotechnological interventions for the conservation of genetic diversity of Philippine native pigs, chickens, and ducks" implemented by the IAS, CAFS, UPLB.

\section{REFERENCES}

Abouelezz, F. M., M.A. Sayed, \& J. Santiago-Moreno. 2017. Fertility disturbances of dimethylacetamide and glycerol in rooster sperm diluents: Discrimination among effects produced pre and post freezing-thawing process. Anim. Reprod. Sci. 184:228-234. https://doi.org/10.1016/j. anireprosci.2017.07.021

Aitken, R.J. 2020. Impact of oxidative stress on male and female germ cells: implications for fertility. Reprod. 159: R189-R201. https://doi.org/10.1530/REP-19-0452

Aramli, M., M. Kalbassi, R. Nazari, \& S. Aramli. 2013. Effects of short-term storage on the motility, oxidative stress, and ATP content of Persian sturgeon (Acipenser persicus) sperm. Anim. Reprod. Sci. 143:112-117. https://doi.org/10.1016/j. anireprosci.2013.10.010

Atifah, Y., Y. Sistina, \& D.M. Saleh. 2018. Morphology of local duck (Anas platyrhyncos) spermatozoa post preservation in different medium combined in egg yolk cryoprotectant. BioLink. 4:121-129. https://doi.org/10.31289/biolink. v4i2.970

Aya, R.A. 2018. Genetic improvement of Itik Pinas to be continued in new R\&D facility. http://www.pcaarrd.dost.gov.ph/ home/portal/index.PhP/quick-information-dispatch/3217genetic-improvement-of-itik-pinas-to-be-continued-innew-r-d-facility

Bansal, A. K. \& G. S. Bilaspuri. 2011. Impacts of oxidative stress and antioxidants on semen functions. Vet. Med. Int. 11:1-7. https://doi.org/10.4061/2011/686137

Blanch, E., C. Tomás, L. Casares, E.A. Gómez, S. Sansano, \& I. Giménez. 2014. Development of methods for cryopreservation of rooster sperm from the endangered breed "Gallina Valenciana de Chulilla" using low glycerol concentrations. Theriogenology. 81: 1174-1180. https://doi. org/10.1016/j.theriogenology.2014.01.019

Blanco, J. M., G. Gee, D.E. Wildt, \& A.M. Donoghue. 2011. Comparative cryopreservation of avian spermatozoa: Benefits of non-permeating osmoprotectants and ATP on turkey and crane sperm cryosurvival. Anim. Reprod. Sci. 123:242-248. https://doi.org/10.1016/j. anireprosci.2010.12.005

Blanco, J. M., G. Gee, D.E. Wildt, \& A.M. Donoghue. 2012. Comparative cryopreservation of avian spermatozoa: Effects of freezing and thawing rates on turkey and sandhill crane sperm cryosurvival. Anim. Reprod. Sci. 131:1-8. https://doi.org/10.1016/j.anireprosci.2012.02.001

Bootwalla, S.M. \& R.D. Miles. 1992. Development of diluents for domestic fowl semen. Poult. Sci. J. 48:121-128. https:// doi.org/10.1079/WPS19920012

Borziak, K., A. Fernandez, T. Karr, T. Pizzari, \& S. Dorus. 2016. The Seminal fluid proteome of the polyandrous Red junglefowl offers insights into the molecular basis of fertility, reproductive ageing and domestication. Sci. Rep. 6:35864. https://doi.org/10.1038/srep35864

Burrows, W.H. \& J.P. Quinn. 1935. A method of obtaining spermatozoa from the domestic fowl. Poult. Sci. J. 14: 251-253. https://doi.org/10.3382/ps.0140251
Capitan, S.S. \& O.A. Palad. 1999. Manual for Artificial Breeding of Farm Animals. College of Agriculture Publications Program, Los Baños.

Chen Y. C., H.C. Liu, L.Y. Wei, J.F. Huang, C.C. Lin, E. Blesbois, \& M.C. Chen. 2016. Sperm quality parameters and reproductive efficiency in muscovy duck (Cairina moschata). J. Poult. Sci. 53:223-232. https://doi.org/10.2141/jpsa.0150162

Churchil, R., P. Praveena, \& D. Sharma. 2014. Semen quality parameters, their inter-relationship and post-washing sperm attributes of Rhode Island Red roosters. Vet. World. 7:11171122. https://doi.org/10.1016/j.theriogenology.2017.05.016

Comizzoli, P. 2015. Biobanking efforts and new advances in male fertility preservation for rare and endangered species. Asian J. Androl. 17:640-645. https://doi. org/10.4103/1008-682X.153849

Cyriac, S., L. Joseph, P.A. Peethambaran, K. Narayanankutty, \& K. Karthiayini. 2013. Semen quality characteristics of White Pekin, Kuttanad (Anas platyrhynchos domesticus) and Muscovy (Cairina moschata momelanotus) drakes. Indian J. Anim. Sci. 83: 595-599.

Di Iorio, M., G. Rusco, R. Iampietro, M.A. Colonna, L. Zaniboni, S. Cerolini, \& N. Iaffaldano. 2020. Finding an effective freezing protocol for Turkey semen: Benefits of ficoll as non-permeant cryoprotectant and 1:4 as dilution rate. Animals (Basel). 10:421. https://doi.org/10.3390/ ani10030421

Elliot, G.D., S. Wang, \& B.J. Fuller. 2017. Cryoprotectants: A review of the actions and applications of cryoprotective solutes that modulate cell recovery from ultra-low temperatures. Cryobiology. 76: 74-91. https://doi.org/10.1016/j. cryobiol.2017.04.004

Esguerra, J.M., J.H. Quimio, G.A. Dichoso, C.L. Junsay, V.A. Magpantay, \& P.P. Sangel. 2020. Coconut water with either tomato juice or garlic extract as extender components for Paraoakan native chicken semen at different storage temperatures. Philipp J. Sci. 149: 121-131.

Evangelista-Vargas, S. \& A. Santiani. 2017. Detection of intracellular reactive oxygen species (superoxide anion and hydrogen peroxide) and lipid peroxidation during cryopreservation of alpaca spermatozoa. Reprod. Domest. Anim. 52:819-824. https://doi.org/10.1111/rda.12984

Gerzilov, V. 2010. Influence of various cryoprotectants on the sperm mobility of Muscovy semen before and after cryopreservation. J. Agri. Sci. 2:57-60.

Gerzilov, V., P. Rashev, A. Bochukov, \& P. Bonchev. 2011. Effect of semen extenders on sperm motion of in vitro stored Muscovy drake spermatozoa. Biotech. Anim. Husbandry 27: 733-740. https://doi.org/10.2298/BAH1103733G

Han, X.F., Z.Y. Niu, F.Z. Liu, \& C.S. Yang. 2005. Effect of diluents, cryoprotectants, equilibrium time and thawing temperature on cryopreservation of duck semen. Intern. J. Poult. Sci. 4: 197-201. https://doi.org/10.3923/ijps.2005.197.201

Hu, J., W. Tian, X. Zhao, L. Zan, H. Wang, Q. Li, \& Y. Xin. 2010. The cryoprotective effects of ascorbic acid supplementation on bovine semen quality. Anim. Reprod. 121: 272-77. https://doi.org/10.1016/j.anireprosci.2010.04.180

Huang, X., P. Zhuang, L. Zhang, F. Zhao, J. Liu, G. Feng, \& T. Zhang. 2014a. Effects of cryopreservation on motility characteristics and enzyme activity of sperm in a Chinese fish, Nibea albiflora. Cryo-Letters 35:267-276.

Huang, X., P. Zhuang, L. Zhang, F. Zhao, J. Liu, G. Feng, \& T. Zhang. 2014b. Effect of cryopreservation on the enzyme activity of Russian sturgeon (Acipenser gueldenstaedtii Brandt \& Ratzeburg, 1833) semen. J. Appl. Ichthyol. 30:1585-1589. https://doi.org/10.1111/jai.12608

Ighodaro, O.M. \& O.A. Akinloye. 2018. First line defense antioxidants-superoxide dismutase (SOD), catalase (CAT) and glutathione peroxidase (GPX); Their fundamental role in the entire antioxidant defense grid. Alexandria J. Med. 
54:287-293. https://doi.org/10.1016/j.ajme.2017.09.001

Kadirve, G., S. Kumar, S.K. Gosh, \& P. Perumal. 2014. Activity of antioxidative enzymes in fresh and frozen thawed buffalo (Bubalus bubalis) spermatozoa in relation to lipid peroxidation and semen quality. Asian Pac. J. Reprod. 3: 210217. https://doi.org/10.1016/S2305-0500(14)60028-2

Kasai, K. \& A. Izumo. 2001. Efficiency of artificial vagina method in semen collection from Osaka Drakes. J. App. Poult. Res. 10:206-210. https://doi.org/10.1093/japr/10.3.206

Khaeruddin, K., M. Kurniawan, \& S. Soman. 2019. Cryopreservation of Kampung rooster semen using egg yolk diluent from four types of poultry with different concentrations. J. Ked. Hewan. 13: 60-65. https://doi. org/10.21157/1021157/j.ked.hewan.vl3i3.14892

Khan, R.U. 2011. Antioxidants and poultry semen quality. World Poult. Sci. J. 67:297-308. https://doi.org/10.1017/ S0043933911000316

Kim, S., Y. Lee, \& Y. Kim. 2011. Changes in sperm membrane and ROS following cryopreservation of liquid boar semen stored at $15^{\circ} \mathrm{C}$. Anim Reprod Sci. 124:118-124. https://doi. org/10.1016/j.anireprosci.2011.01.014

Lasso, J.L., E.E. Noiles, J.G. Alvarez, \& B.T. Storey. 1994. Mechanism of superoxide dismutase loss from human sperm cells during cryopreservation. J. Androl. 15: 255265. https://doi.org/10.1002/j.1939-4640.1994.tb00444.x

Lone, S. A., J.K. Prasad, S.K. Ghosh, G.K. Das, B. Balamurugan, \& M.R. Verma. 2018. Study on correlation of sperm quality parameters with antioxidant and oxidant status of buffalo bull semen during various stages of cryopreservation. Andrologia. 50(4). https://doi.org/10.1111/and.12970

Long, J.A. 2006. Avian semen cryopreservation: what are the biological challenges? Poult. Sci. J. 85:232-236. https://doi. org/10.1093/ps/85.2.232

Long, J.A, D.C. Bongalhardo, J. Pelaéz, S. Saxena, P. Settar, N.P. O'Sullivan, \& J.E. Fulton. 2010. Rooster semen cryopreservation: Effect of pedigree line and male age on postthaw sperm function. Poult. Sci. 89: 966-973. https://doi. org/10.3382/ps.2009-00227

Majhi, R. K., A. Kumar, M. Yadav, P. Kumar, A. Maity, S. C. Giri, \& C. Goswami. 2016. Light and electron microscopic study of mature spermatozoa from White Pekin duck (Anas platyrhynchos): An ultrastructural and molecular analysis. Andrology. 4:232-244. https://doi.org/10.1111/ andr.12130

Malik, A., A.W. Haron, R. Yusoff, M. Nesa, M. Bukar, \& A. Kasim. 2013. Evaluation of the ejaculate quality of the red jungle fowl, domestic chicken, and bantam chicken in Malaysia. Turk. J. Vet. Anim. Sci. 37: 564-568. https://doi. org/10.3906/vet-1107-26

Marti, E., J.I. Marti, T. Muiño-Blanco, \& A. Cebrián-Pérez. 2008. Effect of cryopreservation process on the activity and immunolocalization of antioxidant enzymes in ram spermatozoa. J. Androl. 29: 459-467. https://doi.org/10.2164/ jandrol.107.003459

Mphaphathi, M. L., D. Luseba, B. Sutherland, \& T.L. Nedambale. 2012. Comparison of slow freezing and vitrification methods for Venda cockerel's spermatozoa. Open J. Anim. Sci. 2:204-210. https://doi.org/10.4236/ ojas.2012.23028

Mohanty, T.K., S.A. Lone, A. Kumaresan, A. Bhakat, R. Kumar, R.K. Baithalu, R. Sinha, A.R. Paray, H.P. Yadav, S.K. Sahu, \& A.K. Mohanty. 2018. Sperm dosage and site of insemination in relation to fertility in bovines. Asian Pac. J. Reprod. 7:1-5. https://doi.org/10.4103/2305-0500.220977

Mossa, R.K. 2006. Characterization of Iraqi local drake ejaculate and effect of frequency of collection in sperm quality. Bas. J. Vet. Res. 5 :146-152. https://doi.org/10.33762/ bvetr.2006.59047

Nahak, A.K., S.C. Giri, D.N. Mohanty, P.C. Mishra, \& S.K.
Dash. 2015. Effect of frequency of collection on seminal characteristics of White Pekin duck. Asian Pac. J. 4:70-73. https://doi.org/10.1016/S2305-0500(14)60062-2

Nor-Ashikin M. N. \& R. B. Abdullah. 2011. Comparison between tris-citric acid yolk, yolk albumin citrate and skimmed milk extenders on sperm motility, livability and mass movement in frozen-thawed goat sperm. Biomed. Res. 22(3).

Orzołek, A., P. Wysocki, J. Strzezek, \& W. Kordan. 2013. Superoxide dismutase (SOD) in boar spermatozoa: Purification, biochemical properties and changes in activity during semen storage $\left(16^{\circ} \mathrm{C}\right)$ in different extenders. Reprod. Biol. 13:34-40. https://doi.org/10.1016/j. repbio.2013.01.176

Partyka, A, E. Łukaszewicz, \& W. Niżański. 2012a. Effect of cryopreservation on sperm parameters, lipid peroxidation and antioxidant enzymes activity in fowl semen. Theriogenology. 77: 1497-1504. https://doi.org/10.1016/j. theriogenology.2011.11.006

Partyka, A, E. Łukaszewicz, \& W. Niżański. 2012b. Lipid peroxidation and antioxidant enzymes activity in avian semen. Anim. Reprod. 134:184-190. https://doi.org/10.1016/j. anireprosci.2012.07.007

Partyka, A., W. Niżański, J. Bajzert, E. Łukaszewicz, \& M. Ochota. 2013. The effect of cysteine and superoxide dismutase on the quality of post-thawed chicken sperm. Cryobiology 67: 132-136. https://doi.org/10.1016/j. cryobiol.2013.06.002

Parungao, A.R. 2016. Itik Pinas to boost the balut industry through increased duck egg production. http:// www.pcaarrd.dost.gov.ph/home/portal/index.PhP/ quick-information-dispatch/2751-itik-pinas-to-boostthe-balut-industry-through-increased-duck-eggproduction?platform=hootsuite

Parungao, A.R. 2017. ITIK PINAS: Development, promotion and utilization in building rural enterprises. http://www. pcaarrd.dost.gov.ph/home/portal/index.PhP/quick-information-dispatch/2970-itik-pinas-development-promotionand-utilization-in-building-rural-enterprises

Pelaéz, J., D.C. Bongalhardo, \& J.A. Long. 2011. Characterizing the glycocalyx of poultry spermatozoa: III. Semen cryopreservation methods alter the carbohydrate component of rooster sperm membrae glycoconjugates. Poult. Sci. 90: 435-443. https://doi.org/10.3382/ps.2010-00998

Perumal, P. 2014. Effect of superoxide dismutase on semen parameters and antioxidant enzyme activities of liquid stored $\left(5^{\circ} \mathrm{C}\right)$ mithun (Bos frontalis). Semen. J. Anim. 2014:19. https://doi.org/10.1155/2014/821954

Pinca, A., H. Bautista, C. Adiova, \& P. Sangel. 2019. Comparative expression analysis of small intestine nutrient transporters sodium/glucose cotransporter 1 (SGLT1) and peptide transporter 1 (PepT1) between Itik Pinas (Anas platyrhynchos L.) and commercial layer chicken (Gallus gallus domesticus). Philipp J. Sci. 148:433-439.

Rakha, B.A., M.S. Ansari, S. Akhter S, I. Hussain, \& E. Blesbois. 2016. Cryopreservation of Indian red jungle fowl (Gallus gallus murghi) semen. Anim. Reprod. 174:45-55. https://doi.org/10.1016/j.anireprosci.2016.09.004

Rakha, B.A., M.S. Ansari, S. Akhter, \& E. Blesbois. 2018. Cryoprotective effect of glycerol concentrations on Indian Red Jungle Fowl (Gallus gallus murghi) spermatozoa. Avian Biol. Res. 11:80-88. https://doi.org/10.3184/1758156 $18 \times 15180876264262$

Saint Jalme, M., R. Lecoq, F. Seigneurin, E. Blesbois, \& E. Plouzeau. 2003. Cryopreservation of semen from endangered pheasants: The first step towards a cryobank for endangered avian species. Theriogenology 59:875-888. https://doi.org/10.1016/S0093-691X(02)01153-6

Slowinska, M., E. Liszewska, S. Judycka, M. Konopka, \& A. 
Ciereszko. 2018. Mitochondrial membrane potential and reactive oxygen species in liquid stored and cryopreserved turkey (Melagris galopavo) spermatozoa. Poult. Sci. 97: 3709-3717. https://doi.org/10.3382/ps/pey209

Strzeżek, R, M. Koziorowska-Gilun, \& M. Stawiszyńska. 2012. Cryopreservation of canine semen: the effect of two extender variants on the quality and antioxidant properties of spermatozoa. Pol. J. Vet. Sci. 15: 721-726. https://doi. org/10.2478/v10181-012-0109-0

Surai, P.F. \& Wishart G.J. 1996. Poultry artificial insemination technology in the countries of the former USSR. World Poult. Sci. J. 52:27-43. https://doi.org/10.1079/WPS19960003

Surai, P.F., E. Blesbois, I. Grasseau, T. Chalah, J.-P. Brillard, G.J. Wishart, S. Cerolini, \& N.H.C. Sparks. 1998. Fatty acid composition, glutathione peroxidase and superoxide dismutase activity and total antioxidant activity of avian semen. Comp. Biochem. Phys. A. 120-527-533. https://doi. org/10.1016/S0305-0491(98)10039-1

Surai, P.F., J.P. Brillard, B.K. Speake, E. Blesbois, F. Seigneurin, \& N.H. Sparks. 2000. Phospholipid fatty acid composition, vitamin E content and susceptibility to lipid peroxidation of duck spermatozoa. Theriogenology 53:1025-1039. https://doi.org/10.1016/S0093-691X(00)00249-1

Surai, P.F. 2016. Antioxidant systems in poultry biology: superoxide dismutase. J. Anim. Res. 1: 1-17. https://doi. org/10.21767/2572-5459.100008

Surai, P. F., I.I. Kochish, V.I. Fisinin, \& M.T. Kidd. 2019. Antioxidant defence systems and oxidative stress in poultry biology: an update. Antioxidants (Basel). 8: 235. https:// doi.org/10.3390/antiox8070235

Svoradová, A., L. Kuželova, J. Vašíček, A. Baláži, \& E. Hanusová. 2018. In vitro effect of various cryoprotectants on the semen quality of endangered Oravka chicken. Zygote 26: 3339. https://doi.org/10.1017/S0967199417000685

Tatone, C., G. Di Emidio, M. Vento, R. Ciriminna, \& P.G. Artini. 2010. Cryopreservation and oxidative stress in reproductive cells. Gynecol. Endocrinol. 26:563-567. https:// doi.org/10.3109/09513591003686395
Telnoni, S.P., R. Iis Arifiantini, T.L. Yusuf, \& S. Darwati. 2017. SK Kedu semen cryopreservation in beltsville poultry semen extender and lactated ringer's-egg yolk extender using dimethyl sulfoxie. Asian J. Poult. Sci. 11: 14-19. https:// doi.org/10.3923/ajpsaj.2017.14.19

Thelie, A., A. Bailliard, F. Seigneurin, T. Zerjal, M. Biochard, \& E. Blesbois. 2019. Chicken semen cryopreservation and use for the restoration of rare genetic resources. Poult. Sci. 98:446-455. https://doi.org/10.3382/ps/pey360

Van Voorst, A. \& F.R. Leenstra. 1995. Effect of dialysis before storage or cryopreservation on fertilizing ability of fowl semen. Poult. Sci. J. 74: 141-146. https://doi.org/10.3382/ ps.0740141

Wang, X., X. Shi, Y. Liu, D. Yu, S. Guan, Q. Liu, \& J. Li. 2016. Effects of chilled storage and cryopreservation on sperm characteristics, antioxidant enzyme activities, and lipid peroxidation in Pacific cod Gadus microcephalus. Chin. J. Oceanol. Limn. 34:763-771. https://doi.org/10.1007/ s00343-016-5088-z

Wang, Y., R. Branicky, A. Noë, \& S. Hekimi. 2018. Superoxide dismutases: Dual roles in controlling ROS damage and regulating ROS signaling. J. Cell. Biol. 217:1915-1928. https://doi.org/10.1083/jcb.201708007

Zakošek Pipan, M., J. Mrkun, M. Kosec, A. Nemec Svete, \& P. Zrimšek. 2014. Superoxide dismutase: a predicting factor for boar semen characteristics for short-term preservation. Hindawi 2014:1-7.https://doi.org/10.1155/2014/105280

Zaniboni L., C. Cassinelli, M.G. Mangiagalli, T.M. Gliozzi, \& S. Cerolini. 2014. Pellet cryopreservation for chicken semen: effects of sperm working concentration, cryoprotectant concentration and equilibration time during in vitro processing. Theriogenology 82:251-8. https://doi. org/10.1016/j.theriogenology.2014.04.007

Zawadzka J., E. Łukaszewicz, \& A. Kowalczyk. 2015. Comparative semen analysis of two Polish duck strains from a conservation programme. Europ. Poult. Sci. 79. 